\title{
ORGANIZATIONAL CLIMATE AND COUNTERPRODUCTIVE WORK BEHAVIORS - THE MODERATING ROLE OF GENDER
}

\author{
AGNIESZKA LIPIŃSKA-GROBELNY \\ University of Lodz, Łódź, Poland \\ Institute of Psychology
}

\begin{abstract}
Objectives: The aim of the research was to check whether the organizational climate explains behaviors harmful to the organization. Theoretical justification for the research was provided by the Stressor-Emotion Model by Spector and Fox (2005), in which various stressors lead to the depletion of resources, which in effect favors engaging in unethical work behaviors. Material and Methods: The research was conducted with the participation of 230 people aged 19-67 (125 women and 105 men) with at least 1 year of seniority. The following set of techniques was used: the Organizational Climate Questionnaire by Kolb, the Counterproductive Work Behaviors-Checklist by Spector et al., and metrics. Results: The obtained results indicate that the higher the employees assess the climate in the company, the rarer counterproductive work behaviors (CWBs) appear in the form of abuse, sabotage, theft and withdrawal, both in the group of women and men. All the dimensions of the organizational climate, such as the level of responsibility, requirements, organization, evaluation of awards, management, and the sense of warmth and support, are important for this relationship. The moderating role of gender in the relationship between organizational climate and CWBs was achieved for sabotage and withdrawal, and the following environmental conditions: organizational climate, responsibility, requirements, and organization. Conclusions: These results may be applied in designing a supportive organizational climate to weaken CWBs such as abuse, sabotage, theft and withdrawal. Int J Occup Med Environ Health. 2021;34(4):513-25
\end{abstract}

Key words:

gender, abuse, organizational climate, sabotage, theft, organizational withdrawal

\section{INTRODUCTION}

Counterproductive work behaviors (CWBs) are not a sideeffect of contemporary changes taking place in organizations or the labor market. Conflicts, struggle and violence are an integral part of social processes and occur in every group [1]. There are no organizations without any overt or covert acts of vandalism or cases of harassment, theft, taking advantage of unauthorized sick leaves, deliberate coming late to work or prolongation of breaks. The financial losses resulting from such behaviors are often difficult to estimate, not to mention the non-financial losses such as the loss of a company's good name or technological secrets. Since organizations have to face not the third but the fourth industrial revolution, symbolized by smart factories and mass digitization, the question of why employees harm their organizations should not remain unanswered.

Therefore, an analysis of the determinants of CWBs is of utmost importance to understand the problem under consideration, which may help to develop effective methods of minimizing them. According to Karczewski [2], the direct causes of such behaviors include, among others:

Received: March 12, 2020. Accepted: November 13, 2020.

Corresponding author: Agnieszka Lipińska-Grobelny, University of Lodz, Institute of Psychology, Smugowa 10/12, 91-433 Lódź, Poland (e-mail: alipinskagrobelny@gmail.com). 
- social consent to unethical behavior in the workplace,

- a lack of mainly moral authorities,

- a negative impact of the organizational climate on the employee,

- a lack of correct behavior patterns,

- fatigue and a fast pace of life, which lead to increasingly less time to reflect on the rightness of one's actions.

Baka [3] summarized the approaches to research on the causes of organizationally harmful behaviors, which were adopted in literature, and wrote about a personality trend visible in the analyses, e.g., by Douglas and Martinko [4], an environmental trend applied, e.g., by Spector and Fox [5], and an interactive trend used by Baka [3] or Folger and Skarlicki [6].

This article assumes that a CWB is a reaction to stressors present in the work environment. Therefore, a decision was made to check whether the organizational climate and its individual dimensions explain behavior that is harmful to the organization, and whether gender moderates the relationships under consideration. The analyses to date have omitted this type of moderation, and this may have a significant impact on both results and practical implications, since numerous meta-analyses demonstrate that men are usually much more aggressive than women [7].

As late as in the 1950s, researchers began exploring various behaviors that harmed organizations, most often verifying individual acts and later discovering that they correlated with each other and formed a single category. In order to name it, Hogan and Hogan [8] used the term "an offense against the organization"; Robinson and Bennet [9] wrote about employee deviations; Skarlicki and Folger [10] talked about retaliation behavior, while Spector and Fox [5], whose approach is crucial in the presented article, used the term "counterproductive work behaviors." Macko [11] and Baka [3] extensively reviewed the definition of negative behaviors in the working environment. Despite the differences in the way this term is conceptualized, the following definition of CWBs emerges: voluntary actions that harm, or are intended to harm, organizations and people. The mentioned voluntariness, intentionality, organizational harm, and moral detachment make it possible to distinguish CWBs from other types of behaviors in the organization, e.g., those that are accidental or result from an employee's ignorance or lack of skills.

Based on a literature analysis, Spector et al. [12] distinguished 5 categories of counterproductive behavior patterns at work. These are: abuse, sabotage, theft, production deviance, and organizational withdrawal. The authors of the Polish elaboration of the CWB questionnaire, i.e., Baka et al. [13], present a 4-factor model that is best suited to the data and, therefore, recommended. The model is based on the following types of unethical work behaviors: abuse, sabotage, theft, and organizational withdrawal.

Abuse refers to a variety of violent actions and behaviors that are intended to cause harm or to refrain from providing assistance in an emergency situation. These include physical aggression, harassment, unpleasant comments, threats, bullying at work, showing indecent gestures and mobbing. Spector et al. [12] combined abuse with hostile aggression. Sabotage, the second category of CWBs, is an activity that boils down to causing damage in the workplace. Also in this case, hostile aggression comes at play, except that its object is not people, but the resources of the organization in the form of equipment, tasks or work processes. Like sabotage, theft (the third category of CWBs) is classified as a manifestation of aggressive behavior directed against the company of a more instrumental than hostile nature. One of the most important causes of theft is the feeling of being treated unfairly. The last type of CWBs is withdrawal, treated as an example of instrumental aggression. It consists in the fact that an employee consciously "withdraws" from the time spent at work, allocating increasingly less energy to professional duties. Such behavior includes coming to work a few or dozen or so minutes later, leaving the position before the end of time, 
prolonging breaks, performing tasks for too long, simulating to the employer that you are sick or "cyber loafing," i.e., browsing websites during working hours [13].

The theoretical justification for this research was provided by the Stressor-Emotion Model developed by Spector and Fox [5], in which a variety of stress factors lead to the depletion of resources, which in turn encourages unethical work behaviors. It refers to the transactional theory of stress by Lazarus and Folkman, and assumes that employees monitor their work environment, and then make an individual assessment and interpretation of the events taking place there. If a situation is perceived as a stressor, CWBs (a direct effect) may occur due to negative emotions experienced as a result of being unable to cope with it. The indirect effect also refers to the role of personality traits as mediators of relations between stressors at work and unethical work behaviors. However, this paper focuses on the direct effect of this relationship, with an intention to check whether organizational climate and its individual dimensions determine behavior that is harmful to the organization, and whether gender moderates the said relationships.

A meta-analysis of the environmental determinants of aggression at work shows that among the verified stressors, such as organizational limitations, workload, conflict of roles, ambiguity of roles and interpersonal conflicts, it was the conflicts that were most strongly associated with behavior harmful to the organization [14]. The analyses carried out assume that the source of stress may be organizational climate and its particular characteristics [15]. This is confirmed by the research conducted by Chudzicka-Czupała [16] who pointed to the role of warmth and support, organization and rewards as factors that weaken or, depending on the intensity, reinforce the occurrence of unethical behavior. Hence, the idea was to look again at the relationship between organizational climate and CWBs by deciding on a different way of conceptualizing CWBs, i.e., the typology by Spector et al. [12], mainly because of the broad approach to unethical work behaviors, as well as due to its popularity.

Moving on to organizational climate, the way of defining this term is visible in Kolb [15] (a position important for the research presented in this paper), for whom organizational climate was a set of relatively constant characteristics in the organization perceived by employees, which influence the behavior of all members of the organization [17]. Kolb considered the following aspects of the situation at work to be indicators of organizational climate:

- responsibility, when employees can make decisions and solve problems on their own;

- requirements, relating to encouraging participation in ambitious tasks and projects, and to maintaining high standards of work;

- awards, when good work meets with a reward;

- organization, describing the team's activities as well planned and thought-out, with clear objectives;

- the sense of warmth and support, relating to good social relations;

- management based on high professional and personal competences.

On this basis, Kolb listed 3 main types of organizational climate, i.e., supportive, autocratic and indirect. In supportive climate, employees are given high and clearly defined requirements that stimulate professional development. They are personally responsible for the implementation of the tasks assigned to them. The team's activities are well organized and well thought-out. If necessary, its members can count on the support of their colleagues as well as a competent and friendly superior. Communication in such conditions is bilateral. The opposite of supportive organizational climate is autocratic climate, in which employees are faced with insignificant and vague requirements, for which they are rarely held accountable. Team members are more often punished or criticized when something goes wrong, rather than rewarded and appreciated when they succeed. There is no atmosphere 
of trust and mutual support among employees. Subordinates do not accept their superior, oppose him or her, or give in with reluctance. One-sided communication is most common in such groups [17].

\section{Objectives}

The aim of the research was to check whether organizational climate and its particular characteristics explain CWBs, and whether gender is a moderator of these relationships (Figure 1). As mentioned earlier, the most important subdimensions of organizational climate for the frequency of occurrence of unethical work behaviors, according to Kolb [15], are the sense of warmth and support, rewards and organization. The stronger the sense of warmth and support, the better the organization of work; the better the reward system, the rarer the harmful behaviors in such companies [16].

The next important study regarding the analyzed issues was conducted by Kanten and Er Ulker [18], with the participation of 204 respondents, including 98 men and 106 women. The data received showed that organizational climate explained more than $40 \%$ of the variability of CWBs, and the most important dimensions of organizational climate were the sense of warmth, support and the level of requirements. The higher the intensity of these variables, the rarer the behavior harmful to the organization and the employee. Chernyak-Hai and Tziner [19] also verified the relationship between the perceived organizational climate and unethical work behaviors, achieving a relationship of similar strength and direction as in the previously cited analyses.

Szeliga-Duchnowska [20] conducted a survey in a group of 198 police officers (78 women and 120 men). She wrote about the differentiating role of gender and unethical work behaviors. The respondents of both genders indicated different types of counterproductive behaviors from the typology worked out by Spector et al. [12], which they encountered at work. Men were more likely

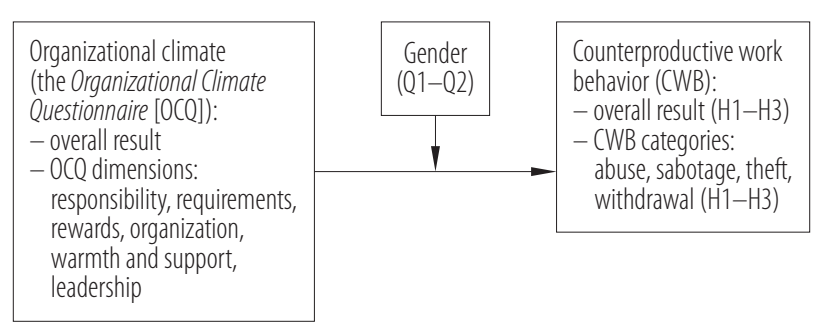

Figure 1. The research model of the moderating role of gender in the relationship between organizational climate and counterproductive work behaviors

to notice abuse and sabotage, while female officers were more likely to point to theft. As the reason, both groups indicated mainly environmental factors: a low pay, organizational injustice and an inefficient control system, but also a lack of job satisfaction or human character. Furthermore, Baka et al. [13] mentioned that men were more often involved in CWBs than women. In turn, the moderating effect of gender in relations between stressors, personality and CWBs was verified by Spector and Zhou [21]. Their analyses involved working undergraduate students $(\mathrm{N}=915)$, with a significant prevalence of women who constituted $78 \%$ of the respondents. The researchers confirmed that gender moderated the relationships described above and explained this by stronger male reactivity to stressors at work.

Due to the deficit of research on the moderating impact of gender on the relations between organizational climate and CWBs, a decision was made to extend the analysis by this type of a relationship and to ask the following research questions:

- Question 1. Does gender moderate the relationship between organizational climate and its individual dimensions and CWBs?

- Question 2. In an environment of low intensity of individual features of organizational climate will men be more likely than women to demonstrate CWBs?

Moreover, in view of the above research, referring to the relationship between organizational climate and its 
subdimensions and organizationally harmful behaviors, the following hypotheses were formulated:

- Hypothesis 1. The higher the assessment of the company's organizational climate, the rarer CWBs can be observed in the form of:

○ H1.1: abuse,

○ H1.2: sabotage,

○ H1.3: theft,

○ H1.4: organizational withdrawal.

- Hypothesis 2. Counterproductive work behaviors are less common in the case of:

○ H2.1: good work organization;

○ H2.2: well-functioning reward system;

O H2.3: warm and supportive atmosphere than in terms opposite to those listed.

- Hypothesis 3. Counterproductive work behaviors are more common in the case of:

○ H3.1: low requirements at work;

○ H3.2: lack of accountability for the work performed;

○ H3.3: poorly competent management than in terms opposite to those listed.

\section{MATERIAL AND METHODS}

The research was conducted among Polish employees with at least 1 year of seniority $(\mathrm{N}=230)$, including 125 women and 105 men. All of them represented various professions such as office personnel, public administration officials, customer service employees and production staff. The age of the respondents ranged 19-67 years $(\mathrm{M}=35.15, \mathrm{SD}=11.29)$. The average age of the women oscillated around 34 years (SD $=10.8)$, while the average age of the men was 37 years $(\mathrm{SD}=11.5)$. The individuals were employed in large organizations hiring over 250 people (35\% of the respondents), medium-sized enterprises $(34 \%)$ or small companies $(31 \%)$. The majority of the respondents, both women and men, had higher education $(53 \%)$. One-third of the respondents (34\%) declared to have secondary education.
The set of questionnaires was dispersed at randomly selected private- and state-owned companies. The anonymity and full confidentiality of the data were ensured. The respondents were asked to complete the questionnaires and to seal them in envelopes, which were subsequently collected by the researcher. The analyses were carried out in accordance with the principles given in the Helsinki Declaration. The respondents were informed that their participation was voluntary, they were fully informed about the purpose and course of the study, and they were assured of their anonymity and the fact that the results would only be used for group analyses.

In order to verify the hypotheses and to answer the questions, the following set of "paper-pencil" type techniques were used: the Organizational Climate Questionnaire (OCQ) by Kolb, the Counterproductive Work BehaviorsChecklist (CWB-C) by Spector et al. [12], and metrics. The OCQ was used to assess subjectively the organizational climate of the company with the following partial dimensions: responsibility, requirements, rewards, organization, sense of warmth and support, leadership, which were evaluated on a 10-point scale. The accuracy of the questionnaire was estimated based on a factor analysis of 6 test items. A 1-factor structure of the discussed tool was obtained. The position's loading factors ranged 0.63-0.79 and explained $48.3 \%$ of the variance [22]. The reliability of the questionnaire ( 6 items, $\mathrm{N}=230$ ), verified in this research using Cronbach's $\alpha$, totaled 0.80 .

The CWB-C was used to measure unethical behaviors at work. The Polish elaboration of the CWB-C questionnaire consists of 32 items. The original 5-dimensional structure of the tool has not been confirmed under Polish conditions. The exploratory factor analysis (EFA) results indicated 4 factors in the Polish version of CWB-C, i.e., abuse, sabotage, theft and organizational withdrawal. The estimation of internal consistency was made using Cronbach's $\alpha$, which oscillated from 0.71 (organizational withdrawal) to 0.93 (the overall result), as well as by means 
of EFA and confirmatory factor analysis (CFA). The reliability of the questionnaire ( 32 items, $\mathrm{N}=230$ ), verified in the present study using Cronbach's $\alpha$, reached a value of 0.69 (theft) to 0.91 (the overall result).

The advantages of the CWB-C questionnaire, in comparison with other "paper-pencil" tools, include a wide range of unethical behaviors, both in terms of types and conditions. Furthermore, CWB-C does not measure individual acts, but categories. As far as other methods of studying unethical behaviors are concerned, e.g., an assessment by colleagues/superiors or direct measurement, it should be stressed that self-description is the one that is most often applied in analyses. It ensures full anonymity of the respondents. What is more, it is the employees themselves who have full knowledge about the frequency of their own actions that are harmful to their organization. Furthermore, Carpenter et al. [23] confirmed that self-description methods are more accurate than external evaluation methods.

\section{RESULTS}

\section{Descriptive statistics}

Statistical analyses were carried out in SPSS Statistics, version 25, using the PROCESS method [24]. Table 1 contains coefficients of correlation between all variables.

It shows that organizational climate remains in a strong positive relationship with responsibility, requirements, rewards, organization, the sense of warmth and support, and leadership. Counterproductive work behaviors correlate strongly positively with abuse, sabotage, theft and organizational withdrawal. Moreover, climate and its subdimensions are negatively associated with abuse, sabotage, organizational withdrawal and CWBs (the overall result). Theft is in a negative relationship with responsibility, organization, leadership and organizational climate.

In addition, it was examined whether men are more likely to engage in CWBs than women (Table 2). Student's t-test scores confirm that men, compared to women, exhibit stronger CWBs, both in general terms $(\mathrm{t}(228)=-2.77$, $\mathrm{p}<0.01)$ and with reference to specific categories of CWBs such as: abuse $(\mathrm{t}(228)=-2.05, \mathrm{p}<0.05)$, sabotage $(\mathrm{t}(228)=-2.61, \mathrm{p}<0.05)$ and organizational withdrawal $(\mathrm{t}(228)=-2.77, \mathrm{p}<0.01)$. Only theft was not differentiated by gender $(\mathrm{t}(228)=-0.98$, n.s. $)$.

\section{Organizational climate and CWBs}

The H1-H3 hypotheses predicted that organizational climate and its subdimensions would be negatively associated with unethical behaviors. The results of the tests confirmed that the higher the rating of the company's organizational climate, the less common the CWBs in the form of abuse, sabotage, theft and withdrawal (Pearson's correlation coefficient ranged $-0.19-(-0.4)$ ) (Table 1). Unethical work behavior is less frequent in situations of good work organization, a well-functioning reward system, as well as a warm and supportive atmosphere. These last 2 properties of organizational climate are of no significance only for theft. In addition, behavior that is harmful to the organization is more common under the conditions of low requirements at work, a lack of responsibility for the work done, as well as poor management and leadership.

In order to identify the most important characteristics of organizational climate, an additional multivariable regression analysis was carried out using the introduction method, in which the independent variables were responsibility, requirements, rewards, organization, the sense of warmth and support, and leadership, and the dependent variable was CWBs together with categories. The results are presented in Table 3. All the models had good matching indicators, explaining $5-18 \%$ of unethical behavioral variability with their categories. For CWBs, the most important exogenous variable turned out to be good work organization $(\beta=-0.27)$, for abuse - rewards $(\beta=-0.19)$ and organization $(\beta=-0.19)$, for sabotage - responsibility $(\beta=-0.18)$ and organization $(\beta=-0.25)$, for theft - again responsibility $(\beta=-0.17)$ and organization $(\beta=-0.17)$, and for withdrawal - organization $(\beta=-0.27)$ and leadership $(\beta=-0.15)$. 


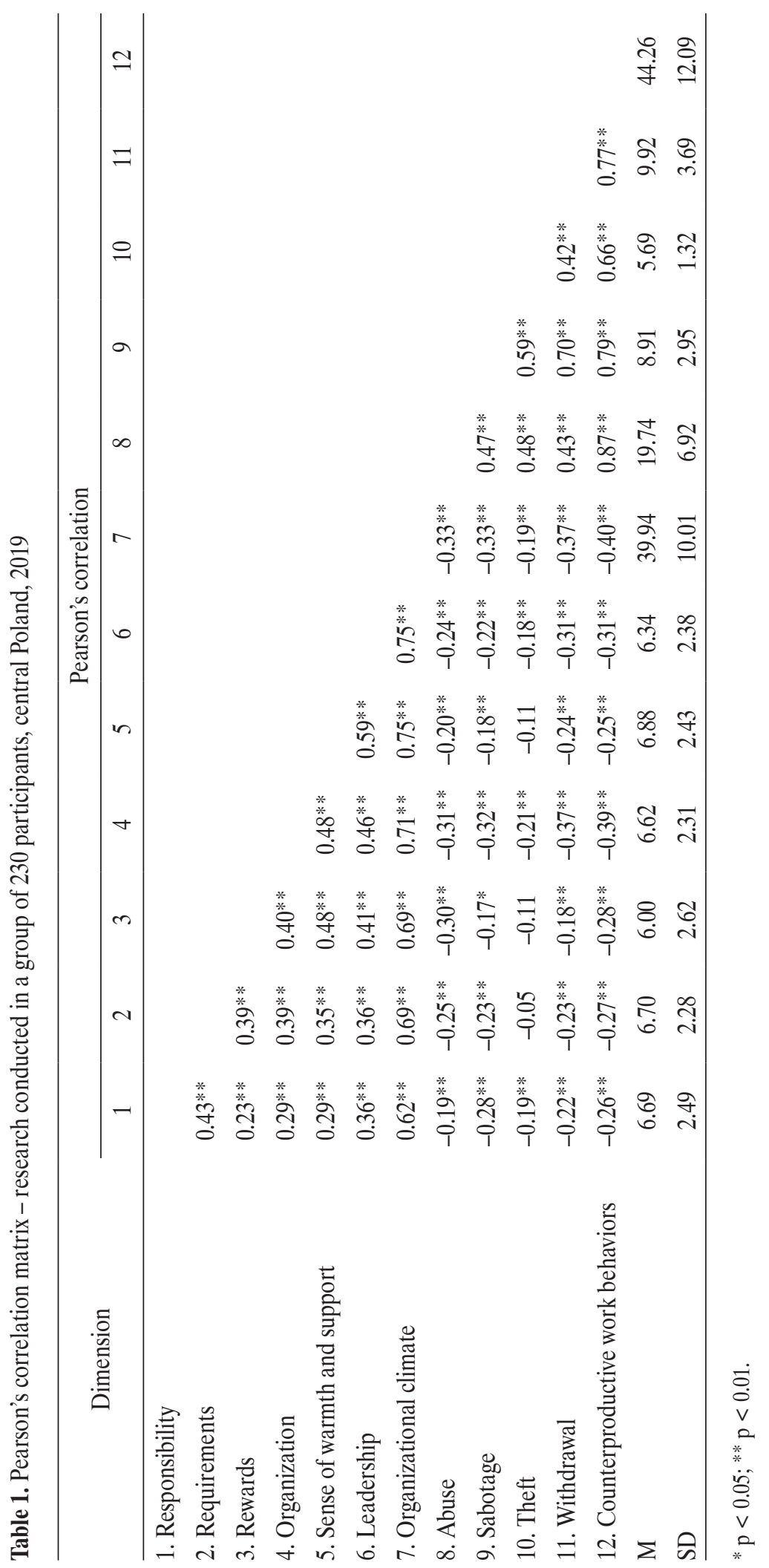


Table 2. Student's t-test scores for gender and counterproductive work behaviors (CWBs) - research conducted in a group of 230 participants, central Poland, 2019

\begin{tabular}{|c|c|c|c|c|c|c|}
\hline \multirow{3}{*}{ CWBs } & \multicolumn{4}{|c|}{$\begin{array}{l}\text { Participants } \\
(\mathrm{N}=230)\end{array}$} & \multirow{3}{*}{$\mathrm{t}(228)$} & \multirow{3}{*}{ Cohen's c } \\
\hline & \multicolumn{2}{|c|}{$\begin{array}{c}\text { women } \\
(\mathrm{N}=125)\end{array}$} & \multicolumn{2}{|c|}{$\begin{array}{c}\text { men } \\
(\mathrm{N}=105)\end{array}$} & & \\
\hline & $\mathrm{M}$ & $\mathrm{SD}$ & M & $\mathrm{SD}$ & & \\
\hline Abuse & 18.89 & 6.25 & 20.75 & 7.55 & $-2.05^{*}$ & 0.27 \\
\hline Sabotage & 8.43 & 2.11 & 9.49 & 3.66 & $-2.61^{*}$ & 0.34 \\
\hline Theft & 5.61 & 1.27 & 5.78 & 1.39 & -0.98 & - \\
\hline Organizational withdrawal & 9.3 & 3.06 & 10.67 & 4.22 & $-2.77^{* *}$ & 0.37 \\
\hline Total & 42.22 & 10.62 & 46.68 & 13.29 & $-2.77^{* *}$ & 0.37 \\
\hline
\end{tabular}

$* \mathrm{p}<0.05 ; * \mathrm{p}<0.01$

\section{The moderating role of gender}

The second research problem (Q1-Q2), which concerned the relationship between organizational climate and its dimensions and CWBs with respect to gender as a moderator, was verified using the PROCESS macro method [24]. It is based on regression analyses and a bootstrapping procedure. In this case, bootstrapping based on a random sampling of 5000 samples with replacement was applied. Model 1 was used in the study, which refers to regression with 1 moderator. Before the calculations were made, the variables were subject to centering. The following 3 effects were tested:

- a direct impact of the exogenous variable (organizational climate and its dimensions) on the endogenous variable $(\mathrm{CWB})$;

- a direct impact of the moderator (gender) on the dependent variable (CWB);

- an effect of interactions between the exogenous variable and the moderator on the endogenous variable. In order to eliminate multicollinearity, separate analyses were carried out for organizational climate and its individual properties.

The moderating role of gender was confirmed in the relationship between organizational climate and sabotage
$(\mathrm{F}(1,226)=6.78, \mathrm{p}<0.01)$, responsibility and sabotage $(\mathrm{F}(1,226)=3.66, \mathrm{p}<0.05)$, requirements and sabotage $(\mathrm{F}(1,226)=4.58, \mathrm{p}<0.05)$, organizational climate and withdrawal $(\mathrm{F}(1,226)=3.86, \mathrm{p}<0.05)$, and organization and withdrawal $(\mathrm{F}(1,226)=4.83, \mathrm{p}<0.05)$. All models were well matched to the data and explained $11-17 \%$ of unethical behavioral variability, and the introduction of the moderator in the form of gender improved the match by 2-3\% (Table 4). Further regression analyses of the interaction effects in the group of women and men revealed that the lower the assessment of organizational climate, the higher the tendency to sabotage, especially in the group of men $(\beta=-0.38)$ compared to women $(\beta=-0.26)$. A similar pattern of results occurred in the relationship of responsibility (organizational climate properties) and sabotage (women $\beta=-0.18$, men $\beta=-0.32$ ), and in the case of requirements and sabotage (women n.s., $\operatorname{men} \beta=-0.32$ ). Low requirements and a failure to assume responsibility for the work performed may be grounds for the deliberate failure to perform, or for the defective performance of, one's professional duties but may also contribute to losses and damage to the organization.

Gender was also involved as a moderator of the relationships between organizational climate and CWBs 
Table 3. Regression coefficients for counterproductive work behaviors (CWBs) and CWB categories: abuse, sabotage, theft, organizational withdrawal - research conducted in a group of 230 participants, central Poland, 2019

\begin{tabular}{|c|c|c|}
\hline Variable & $\beta$ & Adjusted coefficients of determination \\
\hline CWB total & & adj. $\mathrm{R}^{2}=0.18, \mathrm{~F}(6,223)=9.28^{* * *}$ \\
\hline responsibility & -0.11 & \\
\hline requirements & -0.05 & \\
\hline rewards & -0.11 & \\
\hline organization & $-0.27^{* * *}$ & \\
\hline sense of warmth and support & 0.05 & \\
\hline leadership & -0.11 & \\
\hline Abuse & & adj. $R^{2}=0.12, F(6,223)=6.37^{* * *}$ \\
\hline responsibility & -0.04 & \\
\hline requirements & -0.07 & \\
\hline rewards & $-0.19^{*}$ & \\
\hline organization & $-0.19^{*}$ & \\
\hline sense of warmth and support & 0.06 & \\
\hline leadership & -0.07 & \\
\hline Sabotage & & adj. $R^{2}=0.12, F(6,223)=6.42 * * *$ \\
\hline responsibility & $-0.18^{*}$ & \\
\hline requirements & -0.04 & \\
\hline rewards & -0.08 & \\
\hline organization & $-0.25^{* *}$ & \\
\hline sense of warmth and support & 0.03 & \\
\hline leadership & -0.03 & \\
\hline Theft & & adj. $\mathrm{R}^{2}=0.05, \mathrm{~F}(6,223)=3.1^{* *}$ \\
\hline responsibility & $-0.17^{*}$ & \\
\hline requirements & 0.12 & \\
\hline rewards & -0.04 & \\
\hline organization & $-0.17^{*}$ & \\
\hline sense of warmth and support & 0.04 & \\
\hline leadership & -0.08 & \\
\hline Organizational withdrawal & & adj. $\mathrm{R}^{2}=0.15 ; \mathrm{F}(6,223)=7.45^{* * *}$ \\
\hline responsibility & -0.07 & \\
\hline requirements & -0.05 & \\
\hline rewards & 0.02 & \\
\hline organization & $-0.27^{* *}$ & \\
\hline sense of warmth and support & 0.006 & \\
\hline leadership & $-0.15^{*}$ & \\
\hline
\end{tabular}

$* \mathrm{p}<0.05 ;{ }^{* *} \mathrm{p}<0.01 ; * * * \mathrm{p}<0.001$.

${ }^{\mathrm{a}}$ Results of variance analysis. 
Table 4. The moderating role of gender in the relationship between organizational climate and its dimensions with sabotage and organizational withdrawal - research conducted in a group of 230 participants, central Poland, 2019

\begin{tabular}{|c|c|c|c|c|c|}
\hline Variable & $\mathrm{b}$ & SE & $95 \% \mathrm{CI}$ & $\mathrm{R}^{2}\left(\Delta \mathrm{R}^{2}\right)$ & $\mathrm{F}(3,226)$ \\
\hline \multicolumn{6}{|l|}{ Sabotage } \\
\hline \multicolumn{6}{|l|}{ organizational climate } \\
\hline constant & $12.99^{* * *}$ & 0.75 & $11.49-14.48$ & & \\
\hline organizational climate & $-0.1^{* * *}$ & 0.2 & $0.86-3.85$ & & \\
\hline gender & $2.36^{* *}$ & 0.75 & $-0.14-(-0.06)$ & $0.15(0.03)$ & $13.7^{* * *}$ \\
\hline organizational climate $\times$ gender & $-0.04^{* *}$ & 0.2 & $-0.08-(-0.01)$ & & \\
\hline \multicolumn{6}{|l|}{ responsibility } \\
\hline constant & $10.94^{* * *}$ & 0.53 & $9.88-12.00$ & & \\
\hline responsibility & $-0.31^{* * *}$ & 0.07 & $-0.45-(-0.15)$ & & \\
\hline gender & $1.38^{*}$ & 0.53 & $0.32-2.44$ & $0.13(0.02)$ & $9.56^{* * *}$ \\
\hline responsibility $\times$ gender & $-0.14^{*}$ & 0.07 & $-0.29-(-0.02)$ & & \\
\hline \multicolumn{6}{|l|}{ requirements } \\
\hline constant & $11.13^{* * *}$ & 0.58 & $9.88-12.27$ & & \\
\hline requirements & $-0.32^{* * *}$ & 0.08 & $-0.48-(-0.16)$ & & \\
\hline gender & $1.72 *$ & 0.58 & $0.58-2.87$ & $0.11(0.02)$ & $8.88^{* * *}$ \\
\hline requirements $\times$ gender & $-0.17^{*}$ & 0.08 & $-0.33-(-0.01)$ & & \\
\hline \multicolumn{6}{|l|}{ Organizational withdrawal } \\
\hline \multicolumn{6}{|l|}{ organizational climate } \\
\hline constant & $15.52^{* * *}$ & 0.93 & $13.67-17.36$ & & \\
\hline organizational climate & $-0.14 * * *$ & 0.02 & $-0.18-(-0.09)$ & & \\
\hline gender & $2.35^{*}$ & 0.93 & $0.51-4.19$ & $0.17(0.02)$ & $15.76^{* * *}$ \\
\hline organizational climate $\times$ gender & $-0.04^{* *}$ & 0.02 & $-0.09-(-0.01)$ & & \\
\hline \multicolumn{6}{|l|}{ organization } \\
\hline constant & $13.86^{* * *}$ & 0.67 & $12.52-15.2$ & & \\
\hline organization & $0.59^{* * *}$ & 0.09 & $-0.78-(-0.04)$ & & \\
\hline gender & $2.00 * *$ & 0.67 & $0.66-3.33$ & $0.17(0.02)$ & $16.22 * * *$ \\
\hline organizational climate $\times$ gender & $-0.21^{* *}$ & 0.09 & $-0.4-(-0.02)$ & & \\
\hline
\end{tabular}

${ }^{*} \mathrm{p}<0.05 ;{ }^{* *} \mathrm{p}<0.01 ;{ }^{* * *} \mathrm{p}<0.001$.

in the case of organizational withdrawal. Gender reinforces the relationship between organizational climate and withdrawal, as well as between organization and withdrawal. Additional regression analyses conducted in the subgroups revealed that these relationships remained moderate and negative, close to strong (organizational climate: women $\beta=-0.33$, men $\beta=-0.41$; organization: women $\beta=-0.29$, men $\beta=-0.43$ ). The lower the assessment of organizational climate and the level of work organization, the greater the tendency of men in particular to consciously take action aimed at withdrawal from work. 


\section{DISCUSSION}

The aim of the research was to verify whether organizational climate and its individual characteristics explain CWBs, and whether gender is a moderator of these relationships. The results of the research proved to be largely consistent with the assumptions of the Stressor-Emotion Model by Spector and Fox [5], confirming the role of environmental factors of counterproductivity. The lower the rating of the company's organizational climate, the more often CWBs in the form of abuse, sabotage, theft and withdrawal occur. Unethical work behavior is more frequent in the following situations:

- a poor work organization,

- an inadequately functioning reward system,

- an atmosphere devoid of warmth and support,

- the conditions of low requirements,

- a lack of responsibility for the work done,

- poor management and leadership (all H1-H3 hypotheses were confirmed).

The results obtained correspond to those recorded by Chudzicka-Czupała [16], Kanten and Er Ulker [18], or Chernyak-Hai and Tziner [19].

Further analyses made it possible to identify the most important factors that can cause stress and lead to resource depletion, and thus to unethical work behaviors. A low evaluation of the reward system and organization encourages abuse, as it generates strong negative emotions and leads to conflict situations, which, as demonstrated by Spector et al. [12], is crucial to the emergence of such harmful behavior. A low level of responsibility and organization is associated with sabotage and theft. This may involve retaliation against the organization, expression of dissatisfaction and opposition, but on the other hand, it may also mean the need for changes to the working environment [3]. Withdrawal, which qualitatively differs from the CWBs listed above due to its passivity, is most strongly related to work organization and leadership quality. Overall, the most important dimension of organizational climate is good work organization, which protects companies from counterproductivity, both in active (abuse, sabotage, theft) and passive (withdrawal) forms. Good work organization can improve motivation and commitment to work, and can make employees more focused on learning and development. This dimension based on the concept by Kolb also appeared in the analyses conducted by Chudzicka-Czupała [16], despite a different way of conceptualizing the variable of unethical work behaviors.

Moreover, it was confirmed that men are more involved in CWBs than women [13]. This concerns both the overall result and the 3 categories of CWBs, i.e., abuse, sabotage and organizational withdrawal. Only theft remained free of gender differences. The moderating role of gender in the relationship between organizational climate and CWBs was achieved for sabotage and withdrawal and the following environmental conditions: organizational climate, responsibility, requirements, and organization. Just like in the tests by Spector and Zhou [21], higher scores in the counterproductivity categories mentioned were achieved by men. Sabotage refers to active forms of CWBs, triggered by strong negative emotions. Organizational withdrawal, in turn, is a passive form of CWBs, which is associated with instrumental aggression. What these behaviors have in common is that they are organization-oriented and are examples of physical aggression in which men score significantly higher [7,21]. The lower performance of women in CWBs may be due to the fact that they succumb to a non-aggressive autostereotype of their own gender, or that they inhibit their aggressiveness through the sense of guilt or fear of punishment. Finally, the limitations of the analyses carried out should be mentioned. The first limitation is the self-description tool of CWB measurement, which refers to a subjective assessment of being engaged in unethical work behaviors. It is worth recalling, however, that other methods are not free from defects either; self-description methods ensure the anonymity of the respondents, and employees have full knowledge of the frequency of committing organiza- 
tionally harmful acts. Moreover, Carpenter et al. [23] confirmed their greater relevance than that of external methods of CWB evaluation. The second limitation refers to concentrating only on environmental conditions without dispositional variables. The aim was to minimize the risk of a common method bias resulting from the application of the same "paper-pencil" measurement methods.

\section{CONCLUSIONS}

It is worth mentioning once again that there are no organizations where unethical work behaviors do not occur, and financial losses are difficult to estimate, both in terms of direct and indirect costs. Therefore, it is worthwhile to look not only at the determinants of professional effectiveness, but also at the variables explaining negative behaviors at work - in this case the role of organizational climate. Sometimes, it is easier to monitor working conditions in terms of requirements, the level of organization and responsibility for tasks than to take care of the mental and physical well-being of subordinates. Of course, any such program of planned interventions should be preceded by a thorough organizational diagnosis, but there are some dimensions of universal importance, namely work organization, which can still be enriched by actions taken by the employees themselves to match work to the needs and preferences, i.e., by elements of job crafting.

\section{REFERENCES}

1. Sułkowski Ł. [Evolutionism in management. Darwin's managers.] Warszawa: PWE; 2010. Polish.

2. Karczewski L. [Business ethics outlines]. Opole: Oficyna Wydawnicza Politechniki Opolskiej; 2004. Polish.

3. Baka Ł. [Counterproductive behaviour at work]. Why do employees harm the organization? Warszawa: Wydawnictwo Naukowe Scholar; 2017. Polish.

4. Douglas SC, Martinko MJ. Exploring the role of individual differences in the prediction of workplace aggression. J App Psychol. 2001;86(4):547-59.
5. Spector PE, Fox S. The stressor-emotion model of counterproductive work behaviour (CWB). In: Fox S, Spector PE, editors. Counterproductive work behaviour: Investigations of actors and targets. Washington, DC: APA; 2005. p. 190-224.

6. Folger R, Skarlicki DP. A popcorn metaphor for employee aggression. In: Griffin RW, O'Leary-Kelly A, Collins JM, editors. Dysfunctional behaviour in organizations: Violent and deviant behavior. Stamford, CT: Elsevier Science/JAI; 1998. p. 43-81.

7. Wojciszke B. [Agency and community. Basic dimensions of social perception]. Gdańsk: GWP; 2010. Polish.

8. Hogan R, Hogan J. How to measure employee reliability? J App Psychol. 1989;74(2):273-9.

9. Robinson SL, Bennett RJ. A typology of deviant workplace behaviours: A multidimensional scaling study. AMJ. 1985; 38(2):555-72.

10. Skarlicki DP, Folger R. Retaliation in the workplace: The roles of distributive, procedural, and interactional justice. J App Psychol. 1997;82(3):434-43.

11. Macko M. [Sense of organizational justice and employee behaviours]. Poznań: Wydawnictwo Naukowe UAM; 2009. Polish.

12. Spector PE, Fox S, Penney LM, Bruursema K, Goh A, Kessler S. The dimensionality of counterproductivity: Are all counterproductive behaviours created equal? J Voc Behav. 2006;68(3):446-60.

13. Baka $\measuredangle$, Derbis R, Walczak R. [Psychometric properties of the polish version of Counterproductive Work Behaviour Checklist (CWB-C)]. Psychol J. 2015;21(2):163-74. Polish.

14. Hershcovis MS, Turner N, Barling J, Arnold KA, Dupré KE, Inness $\mathrm{M}$, et al. Predicting workplace aggression: A metaanalysis. J App Psychol. 2007;92(1):228-38.

15. Kolb DA. Organizational psychology. An experimental approach. Englewood Cliffs, NJ: Prentice-Hall; 1972.

16. Chudzicka-Czupała A. [Ethical behaviour of a person in an organization]. Katowice: Wydawnictwo UŚ; 2013. Polish.

17. Lipińska-Grobelny A, editor. [The organizational climate and its consequences for the functioning of employees]. Łódź: Wydawnictwo UŁ; 2007. Polish. 
18. Kanten P, Er Ulker F. The Effect of Organizational Climate on Counterproductive Behaviours: An Empirical Study on the Employees of Manufacturing Enterprises. TMR. 2013;2(4): 144-60.

19. Chernyak-Hai L, Tziner A. Relationships between counterproductive work behaviour, perceived justice and climate, occupational status, and leader-member exchange. J Work Org Psychol. 2014;30(1):1-12, https://doi.org/10.5093/ tr2014a1.

20. Szeliga-Duchnowska A. Gender and counterproductive work behaviours among police officers. OM. 2018;116(1995):147-62.

21. Spector PE, Zhou ZE. The moderating role of gender in relationships of stressors and personality with counterproductive work behaviour. J Bus Psychol. 2014;29(4):669-81.
22. Chełpa S. [Validation of the Organizational Climate Questionnaire by Kolb]. Psychol R. 1993;34(3):379-87. Polish.

23. Carpenter N, Rangel B, Jeon G, Cottrell J. Are supervisors and coworkers likely to witness employee counterproductive work behaviour? An investigation of observability and self-observer convergence. Per Psychol. 2017;70(4):843-89, https://doi.org/10.1111/peps.12210.

24. Hayes AF. Introduction to Mediation, Moderation, and Conditional Process Analysis: A Regression-Based Approach. New York: The Guilford Press; 2013.

This work is available in Open Access model and licensed under a Creative Commons Attribution-NonCommercial 3.0 Poland License - http://creativecommons.org/ licenses/by-nc/3.0/pl/deed.en. 